\title{
Public Health Aspects of Civil Defense
}

\author{
By DALe C. CAMERON, M.D., M.P.H.
}

$\mathrm{M}$

AJOR attacks upon the United States by an enemy possessing weapons of modern warfare could produce millions of casualties, making necessary the provision of both medical care and public health services on a scale unprecedented in the history of the world. Already much planning and preparation have gone into the organization of civil defense health services, but much more has yet to be done.

The primary considerations in this paper are the problems involved in providing public health services. Space does not permit a detailed analysis of the many problems involved in providing emergency medical care, but these problems are inexorably intertwined with the public health problems, as will be evident from the discussion. Basic to an understanding of the health aspects of civil defense is a knowledge of the nature of the threat and the requisites for an adequate defense.

\section{Nature of Threat}

The effectiveness and limitations of weapons which may be used and the targets susceptible

Dr. Cameron is medical consultant in the Office of Health Emergency Planning, Office of the Surgeon General, Public Health Service. He participated in the preparation of the Project East River Report on Civil Defense for the Department of Defense, the Federal Civil Defense Administration, and the former National Security Resources Board, from November 1951 to June 1952.

Vol. 68, No. 11, November 1953 of destruction by these weapons are outlined below, and some comments are made on enemy capabilities and objectives.

\section{Nature of Weaporis}

The weapons which must be taken into account in preparing for enemy health services include biological, chemical, radiological, and atomic warfare agents. Since the threat from atomic weapons has been discussed extensively elsewhere $(1, \mathscr{Z})$, this discussion will be limited to other unconventional weapons.

Biological warfare agents include living organisms, toxins, biological products, and chemical plant growth regulators, which may be used to produce deaths or casualties in man, animals, or plants. The possible use of such agents as an instrument of warfare has intrigued the imagination of war planners for centuries. Although disease and epidemics among men have materially affected the course of many wars, recorded instances of deliberate attempts to affect the enemy are few. They provide no objective data on the use and effectiveness of biological agents in actual modern warfare.

Estimates of potential performance of biological agents must rest largely on extrapolation from preventive and treatment experimental data, epidemiology of accidental laboratory infections, hypotheses, and an extensive knowledge of man's ceaseless struggle against human, animal, and crop diseases during the ages. Since most of the problems of waging biological warfare are technical, it must be 
assumed that they either have been solved or that satisfactory solutions are, possible. Civil defense today must therefore take into account the possible use of biological agents.

Chemical warfare agents include toxic chemicals, incendiaries, and smokes, which may bo used to produce deaths or casualties in man, to destroy material, or to provide screening operations against enemy weapons or intelligence. Modern chemistry has added materially to the ways in which the ancient and potent weapon of fire can be used. World War I demonstrated conclusively that toxic chemicals also can be used effectively against man and animals. These facts plus the recent development of nerve gas make it imperative that civil defense preparations include provisions for possible attack with chemical agents.

Radiological warfare agents include radioactive materials, other than atomic bombs. These may be used to impair or kill man, animals, or plants, or to deny or impede access to contaminated objects or areas through threat of casualties. If these agents are used against this country, it would probably be primarily to deny or impede access to contaminated areus and to create confusion rather than to produce physical casualties. Radiological warfare is not viewed as nearly as serious a threat as biological, chemical or atomic warfare at the present time.

Viewed as antipersonnel weapons, biological and chemical agents could rival atomic bombs in destructiveness. From the public health point of view, the problems presented by the possible use of biological and chemical agents of warfare are at least as serious as those involved in possible radiological or atomic attack.

\section{Nature of Target}

The targets of these weapons are man, animals, crops, and physical things. Only atomic bombs, high explosives, fire, and certain chemical agents are particularly useful against both living and inanimate targets, but biological and other chemical agents could be used effectively against man, animals, and crops without destroying other things.

Considering man as a target, enormous num- bers of casualties could result from overt attack with biological or chemical warfare agents, as well as with atomic bombs. Correct use of biological agents by saboteurs could cause large numbers of primary casualties and disruption among selected local population groups, but the secondary spread of disease among men after either covert or overt attack probably would not be especially great, particularly if appropriate public health measures are in effect. The covert use of chemical warfare agents presents more technical difficulties than such use of biological warfare agents.

Animals and fowls are seriously vulnerable to attack with biological agents, and the secondary spread of disease would probably be extensive and fairly rapid. The use of biological warfare agents against crops and forests also appears to present a serious threat if these agents are introduced at the proper time and place by either overt or covert means. The secondary spread of disease among crops and forests is also likely to be extensive, but the buildup would be slower than that among animals.

\section{Enemy Capabilities and Objectives}

The use of these special weapons against us depends not only on the vulnerability of targets but on the enemy's capabilities of production and delivery and upon his objectives and intent. Little can be said about enemy capabilities, but scientific knowledge concerning biological, chemical, and atomic warfare is not restricted to the free nations. Public statements have been made by Government officials to the effect that a potential adversary probably has the ability to deliver whatever weapons he has available $(3,4)$. Thus it is important not to underestimate enemy capabilities.

An enemy's objectives and intent, together with enemy capabilities and target vulnerability, play a vital role in our defense efforts. People will prepare to defend themselves against a particular threat only if they perceive it as real and relatively imminent. Perhaps some of our delay in the development of an effective biological and chemical warfare defense is predicated on a general belief that an enemy would not wish to use such agents on our vul- 
nerable targets even if he had the weapons and means of delivery. Consideration of an enemy's objectives and intent is in the realm of pure speculation, but two points deserve mention.

One of these is the possibility of a future world war being based on a different concept from those of the past. The past two wars were waged primarily against things. An effort was made to destroy the productive capacity of nations, a concept brought sharply into focus by strategic bombing to destroy vital links in the production machine. True, men who were in the way were killed or injured, but the primary target, generally, was the industrial productive capacity. The result has been that many countries, victorious and vanquished alike, have required outside aid during the postwar period in providing food and clothing for their people and in rehabilitating their industries. Many of these postwar sequelae could be avoided by waging a war primarily against man, with the result that the survivors would be fewer in number and would probably have ample physical resources for their sustenance.

It may be argued that our enemies would not attempt to assist this country as we have tried to assist war-torn countries in the past, and this is probably true as far as humanitarian motives are concerned. But consider why potential foes would want to conquer this Nation. It seems reasonable to assume that their purpose .would be to control our productivity in order that they might exploit our economy for their benefit. If this be true, then it also seems reasonable to assume that potential enemies might be interested in preserving, insofar as possible, our industrial capacity, and that, therefore, a future war might be against man rather than against things. Chemical and biological agents would become particularly attractive weapons in such a war.

A second point to be considered in speculating on enemy objectives is the fact that biological and chemical agents, particularly the former, lend themselves admirably to covert attack. The possibilities of weapons particularly useful as covert agents surely would not go unrecognized by an enemy who has a penchant for doing everything possible within his means, short of all-out war, to achieve his ends.

\section{Requisites for Civil Defense}

Both military measures and civil measures are necessary for the provision of an adequate defense against enemy attack with modern warfare weapons.

\section{Military Measures}

Dr. Lloyd V. Berkner in an address at the Minnesota World Affairs Center, University of Minnesota, on September 29, 1952, pointed out that the single most important military factor in our present foreign policy is the development of a strategic striking force (5). He noted further, however, that regardless of the merits of this concept, there comes a time when this approach is not enough. When an enemy has built up a sufficiently large striking force of his own to deliver a "knockout blow," the threat of retaliation loses much of its meaning. Thus, not only must this country develop a strong right arm, but it must also have an effective shield so that it may survive to use the strong right arm.

Such a shield is essential not only from the foreign policy point of view but also from the civil defense standpoint. Only with such a shield can the civil defense problem be made manageable. This country does not have unlimited personnel and physical resources to expend on civil defense efforts. If civil defense is to be successful, the magnitude of the task must be manageable. Any leak through our defensive shield must not completely inundate our civil defense system.

\section{Civil Measures}

In addition to the military measures precedent to a manageable civil defense, the following civil measures are essential:

Sufficient warning must be given of an overt attack, preferably of at least an hour, to allow civil protective measures to be taken. The provision of such warning, however, may well be a military rather than a civil responsibility.

Attack with biological or chemical agents must be detected promptly and the public immediately informed of the attack.

Proper protective devices, such as gas masks and shelters, should be available. Masks appear to be the single most effective and feasible 
protective device against overt biological and chemical warfare.

Every individual must know what action is expected of him in the event of attack not only by atomic weapons but also by biological, chemical, or radiological weapons, which remain "unknowns" to most civilians. As such, they tend to cause widespread speculation as to their destructiveness and to engender unreasoning fear in many people. If civilians are to react rationally, they must have adequate knowledge about the nature of these weapons and their capabilities and limitations.

Health personnel must be prepared to deal with the emergency situation; plans for utilization of health facilities must exist; and certain medical supplies must be available.

\section{Public Health Problems}

Among the civil defense problems with which public health officials will be concerned are the provision of safe water; sewage collection and disposal; garbage and refuse storage, collection, and disposal; food sanitation; control of insects and rodents; household sanitation; detection and identification of illnesses; laboratory services; and prophylactic services. Most of these are essentially local community problems.

\section{Public Water Supply}

To maintain a supply of water adequate in quantity and pressure for fire fighting and, at the same time, to make sure that water does not become a vehicle for the mass transmission of disease, will be a major civil defense problem. Any decision to introduce unpotable water into the water distribution system for fire-fighting purposes should be made on the basis of policies developed jointly by the health, water, and fire departments. The problems occasioned by contaminated water supply systems must be carefully weighed against possible losses from fire. These departments should also collaborate on the development of alternate sources of water supply and measures to protect and repair the water system.

Provision should be made for the emergency purification of water by chlorination and other methods, using portable or fixed equipment, so that medical and other civil defense services, hospitals, welfare mass-care facilities, restaurants, householders, and other consumers will be assured of an adequate supply of potable water. The public should be advised of measures which can be used during extreme emergencies to provide themselves with small amounts of safe drinking water, but reliance should not be placed upon the householders: efforts if it is at all possible to make other arrangements. Adherence to current standard methods of water purification will negate in large part any threat of contamination with biological warfare or chemical warfare agents introduced in advance of the purification process. Special, but not insurmountable, problems will be posed by the introduction of these agents beyond the purification plant. The only present protection is either the maintenance of a high residual chlorine in the water or the introduction of chemical neutralizing agents.

\section{Serwage}

Sewage collection and sewage disposal is not as serious a civil defense problem as might at first be imagined. It is possible that radioactive materials may be carried into the sewer lines and concentrated at the sewage plant, but this is, of course, of concern primarily to sewer works operators and maintenance crews. The disruption of treatment and disposal processes is not likely to produce significant health hazards.

The principal problem will be to prevent the contamination of water and food supplies with sewage from damaged sewers. Such contamination, however, may be prevented by such measures as pumping, temporary diversion, and improvised repair. In general, the repair of water systems would take priority over the repair of sewage systems, particularly of sewage treatment plants.

\section{Garbage and Refuse}

Normal collection services may be abandoned during emergency periods, and collection equipment diverted to more urgent duties. To prevent the development of insect breeding and other nuisances, community refuse handling agencies and health departments must plan to maintain certain minimum services: collection of dead animals and highly putrescible refuse; 
designation of places for emergency storage (such as vacant lots or bombed-out buildings), with provision for the control of insects, rodents, and odors; and activation of emergency landfill disposal sites to supplement or replace normal disposal facilities. These measures are particularly important in the vicinity of emergency mass-feeding centers. Householders will need to know how to store or dispose of their own refuse until temporary storage points are established or until normal services are resumed.

\section{Food Sanitation}

The civil defense problem in food sanitation is to adapt the normal services of the health department and of the food industry to the dangers which will exist in an emergency. A particularly important task will be the supervision of food preparation at mass-feeding centers. Other tasks include evaluating possible contamination of food supplies by sewage, broken glass, biological, chemical, and radiological agents, and other extraordinary contaminants; implementing arrangements for decontaminating, segregating, or destroying such supplies; and arranging for the orderly opening and closing of restaurants and other public eating establishments in accordance with civil defense emergency feeding needs. Routine inspection for contamination with biological and chemical agents of all foods being used, however, is not considered feasible.

\section{Insect and Rodent Control}

Normal control of insects and rodents is usually accomplished by mobile teams of specialists working for health departments, community mosquito control agencies, or commercial rodent and pest control operators, but only a few persons and a limited amount of equipment are involved. The civil defense job is to organize these limited facilities so that they may be readily deployed wherever they may be needed, and to train assisting personnel recruited from outside the vector control field.

\section{Honsehold Sanitation}

Household sanitation will be crucial during any civil defense emergency, for it must be expected that many of the sanitation services which are now taken for granted will be disrupted. One of the most serious problems will be the disposal of excreta in the event of water supply or sewerage failure, particularly for apartment dwellers and others not having access to backyard burial facilities. Two types of containers have been suggested. One is a watertight vessel for the direct collection of all human excreta. The other is a small combustible permeable container which will allow the urine to filter out, thus reducing the volume to be stored and collected. A suitable permeable container is not currently available.

\section{Emergency Lodging}

The sanitation problems of emergency lodging are essentially those discussed previously, that is, water supply, refuse disposal, toilet facilities, and the like. In addition, health authorities must establish criteria on space allocation, ventilation, lighting, and safety precautions at entries and exits.

\section{Epidemic Intelligence}

Early detection and identification of illnesses which may result from covert or overt attack with biological or chemical agents and early clarification of the methods of dissemination are extremely important in minimizing the effects of attack and alerting for future covert attacks. The principal problem will probably be in the field of biological warfare, for the victims of modern chemical warfare agents should be readily recognized. Epidemic intelligence may provide the first clue that a covert biological warfare attack has taken place.

Local health departments ordinarily investigate unusual outbreaks of disease, encourage prompt reporting of infectious diseases by physicians and hospitals, and provide laboratory services for the identification of infectious agents. All these services will be necessary for epidemic intelligence; therefore, integration of the normal peacetime functions of health departments with civil defense activities is essential. Mobile epidemiological teams may be needed to assist local health departments in carrying out epidemic intelligence activities during an emergency.

Another important aspect of epidemic intelligence is the need for emergency research dur- 
ing and immediately after any overt attack so that the nature and effectiveness of the weapons used and the effectiveness of the civil defense countermeasures can be evaluated. Such evaluations may aid in saving lives in future attack. Specific, scientific teams should be assigned to obtain the necessary data.

\section{Laboratory Services}

The many laboratories in local, State, and Federal public health agencies; in medical, dental, veterinary, and other teaching institutions; and in private and commercial organizations can provide the laboratory services needed during an emergency for the preservation and restoration of normal sanitation activities, for the identification of biological warfare agents, and in some instances for the preparation of immunizing materials. Clinical laboratory services for the treatment of hospitalized and nonhospitalized patients are present in most hospitals, but these will have to be expanded greatly to deal with the large numbers of casualties expected from an overt attack. The personnel in these laboratories are, of course, familiar with basic laboratory procedures, but it is essential that special training be given in the use of instruments and techniques for dealing with the chemical agents and exotic organism that may be used. Such training is necessary not only for existing personnel but also for the many auxiliary workers who will be needed.

\section{Prophylactic Services}

Atomic disaster would increase the spread of natural communicable diseases because of the disruption of sanitation services and the inevitable crowding of people under relatively poor hygienic conditions. If biological warfare agents should also be used, the dangers of disease spread would be further increased.

The National Research Council has recommended that all persons, adults and children alike, be immunized against tetanus because of the danger of infection following burns and other injuries. The Association of State and Territorial Health Officers, because of the practical difficulties involved in such a program, prefers instead to promote the immunization of children.
The practical limitations of any immunization program at this time are recognized, but it is suggested that the immunization of children against diphtheria and whooping cough and of both children and adults against tetanus and smallpox be encouraged and that substantial quantities of these immunizing agents be stockpiled against a future emergency. These stockpiles will be needed in the event of an actual attack and might be used even before an attack if the situation becomes so critical that people become convinced of the necessity for such immunizations.

\section{Suggestions for Action}

A few suggestions for action to meet some of the public health problems have been given in connection with the discussion of these items. There remain several broad recommendations affecting both public health and medical care problems which deserve special emphasis.

\section{Local Casualty Estimates}

In estimating the number of casualties, most of the local civil defense health service planning has been concerned with the physical casualties following atomic attack. Little consideration has been given to possible casualties from bacteriological and chemical warfare agents and to psychiatric casualties from any type of attack. It is believed that metropolitan area civil defense personnel should make estimates of such casualties on the basis of local and other information. It is suggested that estimates of psychiatric casualties from a sudden catastrophic attack might be predicated on a rate of approximately 1 such casualty for each 4 to 6 physical casualties.

\section{Strengthening Local Services}

Most local civil defense health organizations are not now ready to deal effectively with a major enemy attack directly involving the civilian population, although, of course, some are better prepared than others. Many programs are lagging seriously because of a lack of personnel with medical administrative experience who can devote full time to recruiting, organizing, and training a "hard core" of regular civil defense health workers. 
The civil defense health service should be developed according to a phased schedule, involving motivation, planning, development of organization, and recruiting and training of leaders and workers. Emphasis at the present time should be on the development of a "hard core" of regular civil defense health workers rather than on the recruiting of millions of volunteers. School buildings and other structures should be earmarked for possible use as temporary hospitals and first-aid stations. Oceangoing, lake, and river vessels should also be considered as possible temporary hospitals. Health departments, particularly in urban areas, should bring their epidemic intelligence services to a high degree of proficiency.

\section{Mobile Support}

A marked disparity will undoubtedly exist between the number of trained personnel and physical facilities needed to provide even minimal civil defense health services and the number available, even if all present and projected health resources are available after an attack. Furthermore, an atomic attack could destroy most of the health personnel and facilities in the target area, and biological or chemical attack on an unprepared population could destroy or incapacitate most of the health personnel even though the facilities may be spared. Thus, people in target areas surviving such attacks may have to rely almost exclusively on medical aid from outside the target areas.

Local hospitals and health organizations have done very little planning for the utilization of outside aid, though many of them have given considerable attention to the vital first step of self-help. Accordingly, it is believed that local, State, regional, and Federal civil defense health planners should give increased emphasis to plans for mobile support by medical and public health personnel and for the use of medical facilities at a distance from target areas. The validity of such plans must be assessed by regional test exercises.

\section{Rehabilitation Policies}

The development of sound emergency health service plans could be accelerated by establishing national policy on such questions as the extent to which individual and community med- ical rehabilitation is to be carried out or financed by Federal, State, and local official and voluntary agencies; the relation of medical rehabilitation to other rehabilitation activities; the nature of war risk insurance, if any. Health services which make optimum provision for the smooth transition from short-term emergency actions to long-term rehabilitation activities and which assure continuity of care for the injured depends on clarifying these problems.

\section{Utilization of Health Manpower}

Much remains to be done to assure maximum effectiveness in the use of the critically short supply of professional and subprofessional health personnel in all categories. The majority of treatment activities, short of surgery, will have to be carried out by technical aids under professional supervision. Therefore, careful study of medical, nursing, and other health functions necessary during an emergency should be made to determine which of the activities usually performed by professional and subprofessional personnel can be delegated to less highly trained volunteers working under competent supervision.

\section{Basic Principles}

The purposes of civil defense health services are $(a)$ to minimize the extent and severity of, and provide treatment for, civilian casualties caused by enemy action and $(b)$ to maintain the health of, and provide emergency noncasualty medical service for, evacuees and other individuals deprived of their usual medical care resources.

It is imperative, however, that the normal patient-doctor relationship be reestablished at the earliest possible moment after a disaster so that the current structure for providing health services be affected as little as possible. The established patterns and long-range trends in the provision of health services should not be modified unduly by the necessity to provide emergency mass treatment. It is also imperative that continuity of medical care be maintained for each casualty during the transition between the health emergency and rehabilitation phases. 
These basic principles can best be applied by utilizing to the fullest extent possible existing civilian health services in providing emergency health services.

\section{REFERENCES}

(1) U. S. Scientific Laboratory [Los Alamos, N. Mex.] : The effects of atomic weapons. Prepared for, and in cooperation with, the $U$. S. Department of Defense and the U. S. Atomic Energy Commission. Washington, D. C., U. S. Government Printing Office, 1950.

(2) U. S. Department of Defense : Medical aspects of atomic weapons. Prepared for the National
Resources Board by the U. S. Department of Defense and the U. S. Atomic Energy Commission. Washington, D. C., U. S. Government Printing Office, 1950.

(3) Vandenburg, H. S.: The truth about our air power. Saturday Evening Post 223: 20-21, 100-104 (Feb. 21, 1951).

(4) Twining, N.: Statement made at a joint meeting called by the Secretary of the Air Force and the Federal Civil Defense Administration, June 16, 1952.

(5) Berkner, L. V.: Influence of science and technology on military factors in foreign policies. Address given at the Minnesota World Affairs Center, University of Minnesota. New York, Associated Universities, 1952.

\section{Process for Extracting Andromedotoxin}

Andromedotoxin, a pure compound with therapeutic possibilities in the treatment of hypertension, has been isolated from rhododendron leaves by a modified extraction process developed by two research groups of the National Heart Institute of the Public Health Service. The chemical structure of the drug is still unknown. Not a cure for hypertension, the compound may be useful in lowering the blood pressure in certain cases of hypertension. The compound has not been tested clinically, but trials at Emory University School of Medicine have demonstrated that it temporarily lowers blood pressure in animals. In low doses, it has a strong but brief hypotensive effect.

Special methods for extracting the material, precipitation procedures for eliminating unwanted substances, and chemical steps for purifying the compound by selective absorption were developed by the researchers.

To isolate andromedotoxin, fresh leaves of the native North America species Rhododendron maximum were first chopped, then boiled for an hour, and strained. In appearance, the brew changes during the extraction process from a substance resembling strong black coffee to one with the consistency of new-fallen snow. Of special interest to pharmacologists, the clumpy substance resembles the veratrum alkaloids in physiological actions, but unlike alkaloids, it contains no nitrogen.

More than 1,000 pounds of rhododendron leaves were required to make 1 ounce of the drug. They were collected by the United States Department of Agriculture in North Carolina and West Virginia. The isolation procedures were conducted at the Institute and the pharmacological work was done at Emory. Dr. Neil C. Moran reported on the research at the annual meeting of the American Society for Pharmacology and Experimental Therapeutics at New Haven, Conn., September 7, 1953. 